\title{
Role of Health Literacy on Menstrual Hygiene Practice among the Girl Students
}

\author{
Shanti Prasad Khanal*
}

\begin{abstract}
The main aim of this study was to find out the role of health literacy on menstruation hygiene practice of campus girls. The population of this study were girls studying health and physical education in Surkhet Campus and HA/Staff Nurse in SEDA Campus. Surkhet was selected by proportional stratified sampling. This study followed descriptive and cross-sectional design. The study used two tools Short Test of Functional Health Literacy in Adults (S-TOFHLA) and Self Administrated Questionnaire for collecting data. It was found that health literacy among girls of study area is not satisfactory. The findings indicate that 53.93 percent respondents have adequate health literacy. Adequate health literacy level of girls of HA/Staff nurse, aged 16-18 years and 19-21 years and Chhetri and Janajati had adequate health literary. The findings support that higher proportions of the adequate health literate respondents have good menstruation hygiene practice than inadequate health literate respondents. Finally, the results indicated that health literacy among the girls is inadequate, that calls more concern to the matter of health literacy in educational programs.
\end{abstract}

Key Words: Adequate, inadequate, health literacy, marginal, menstrual hygiene practice,

\section{Introduction}

Health literacy is important not only for health but also for socioeconomic development (Win et al., 2015). Health literacy is a comparatively new concept (Nutbeam, 2000) and new to research in public health (Hepburn, 20I2). Health literacy concept emerges from theories of social exchange, social cognitive and self-efficacy (as cited Hepburn, 20I2). Health literacy has increased in its importance in terms of public health. It is now recognized as a key factor to reduce risky habits (Liu, Liu, $\mathrm{Li}$ and Chen, 2015), an emerging concept that involves the bringing together of people from both the health and literacy fields and builds on the idea that both health and literacy are critical resources for everyday living (WHO, 2009). Health literacy is a key outcome from health education (Nutneam, 2000). Health literacy defined as the 'degree to which individuals have the capacity to obtain, process and understand basic health information and services needed to make appropriate health decisions (Mantwill and Schulz, 20I5). Public health literacy is corresponding to individual health literacy and outcomes include a community's understanding of health messages (Berkman, Davis \& McCormack, 20I0).

Health literacy is important for health of the people. In most countries literacy rates are lower among women than men. There is a clear correlation between inadequate health literacy and poor health outcome. Increasing rates (47\%) of chronic disease are estimated to account for almost half of the total burden of disease. The additional costs of limited health literacy ranges from 3 to $5 \%$ of the total health care cost per year. Health information demands are high but a gap exists between the health-related materials and the reading skills of the audience. Low level of health literacy means that a person is unable to manage their own health effectively, access health services effectively, understand the information and make healthy decisions (WHO, 2008).

\footnotetext{
* MPhil. Scholar, Graduate School of Education, TU, Lecturer, Surkhet Campus Education Email:Skhanal_2008@yahoo.com
} 
Improving the health literacy $(\mathrm{HL})$ of those with the poorest health outcomes is an important tool (WHO, 2008). Lower health literacy is a public health issue (Prothero et. al, 2017). People with low health literacy typically engage in unhealthy behaviours. Young boys and girls (II-12 years) with low HL regarding health/drug knowledge were four times more likely to have smoked than those with high HL. Individuals with low HL may inadequately make use of medical preventive services (Appleton, 20I0). Low health literacy has been linked to inadequate health behaviors and poor health outcomes containing death (Centers for Disease Control and Prevention, 20I5). Adequate health literacy is not always associated with years of formal education (as cited Koh et. al, 2010). Inadequate health literacy is seen across various levels of education that have been shown to be most vulnerable to poor understanding (Hepburn, 2016). Just as, low literacy is linked to low health status and socioeconomic disadvantage (The role of health literacy, 2005). There is general agreement that a relationship exists between health literacy and health outcomes (Neatboom, 2000). Only within the last decade, researchers have recognized the problems associated with health literacy (Speros, 2005).

Above mentioned literatures and concept accomplish that there is a close relationship between health literacy and healthy lifestyle. Person's health status depends upon positive health behaviour and health behaviour depends on literacy level of the people. Limited literacy is linked to several adverse health-related variables, including health care, hospitalization, global measures of health, and some chronic diseases. Health literacy is still in its initial phases of growth, it is however an immense and speedily growing frame of knowledge. However, these all studies were conducted in medical settings. To the best of my knowledge, no studies have been carried out about health literacy and menstrual hygiene management in the context of Nepal. So, this study aimed to explore situation of health literacy and its role on menstruation hygiene practice among the girl students.

\section{Method}

This study followed descriptive and cross-sectional design. Its nature was quantitative. Data was collected from Surkhet Campus (Education) and Surkhet Education Development Academy (SEDA) College of Health Science. All (322) the girl students studying B. Ed majoring HPE in Surkhet Campus (Education) and Health Science (HA and staff nurse) in SEDA Campus of Health Science in Surkhet valley were recruited as study population. All total, I60 girl students studied in BEd Ist, $2^{\text {nd }}$ and $3^{\text {rd }}$ years (Surkhet Campus, 2074) and 162 girl students in HA and Staff Nurse Ist, $2^{\text {nd }}$ and $3^{\text {rd }}$ years (SEDA, 2074). Out of total, I 78 (55.27\%) girl students were selected as a sample by calculating the formula of Solvin (1960). The study used proportional stratified sampling to select the study participants. Two strata were made. One is general education (B. Ed) and another is health science (HA/Staff Nurse). The total population and sampling size of the study is presented in the following table (Surkhet Campus, 2074; SEDA, 2074).

Table I

Study population and sample size of the study.

\begin{tabular}{|c|c|c|c|c|c|c|}
\hline \multirow[t]{2}{*}{ Description } & \multirow[t]{2}{*}{ Category } & \multicolumn{2}{|l|}{ Total } & \multicolumn{2}{|c|}{ Selected Sample (55.27\%) } & \multirow[t]{2}{*}{ total } \\
\hline & & B.Ed & HA/ Staff Nurse & B.Ed & HA/ Staff Nurse & \\
\hline \multirow[t]{3}{*}{ Year } & First & 55 & 54 & 30 & 30 & 60 \\
\hline & Second & 60 & 57 & 33 & 32 & 65 \\
\hline & Third & 51 & 51 & 25 & 28 & 53 \\
\hline Total & & 160 & 162 & 88 & 90 & 178 \\
\hline
\end{tabular}


The study used health literacy scale (Short Test of Functional Health Literacy in Adults (STOFHLA) and Self Administrated Questionnaire as data collection tools. The Nepali Version S-TOFHLA was used to measure the level of health literacy. Earlier self-administrated questionnaire was given to the respondents to fill their answers. Health literacy level of the respondents was analyzed on the basis of scores achieved by the respondents. STOFHLA tool is divided into three levels, like inadequate (score of 0-16) marginal (score of 17-22) and adequate (score of 23-36).

\section{Results and Discussion}

This chapter describes the results and discussion of descriptive study that analyzed the health literacy level and menstruation hygiene management among the girl students of respective campuses.

\section{Results}

In this sub chapter, the data on personal information, situation of health literacy and menstruation hygiene practice of the respondents are analysed.

\section{Situation of Health Literacy}

In order to find out the situation of literacy level of the girl students, S-TOFHLA tool was used. This sub-chapter includes level of health literacy of girl students on the basis of age, caste, stream, educational level, etc.

Health literacy level. STOFHLA tool is divided into three levels, inadequate, marginal and adequate. Literacy in Health Care (n.d.) states that score of 0-16 correct answers indicate inadequate health literacy, 17-22 indicate marginal health literacy and 23-36 indicate adequate health literacy.

Table 2

Health literacy level of girl students

\begin{tabular}{llll}
\hline S.N. & Description & No. & Percentage \\
\hline 1 & Inadequate & 17 & 9.55 \\
2 & Marginal & 68 & 36.51 \\
3 & Adequate & 93 & 53.93 \\
& Total & 178 & 100 \\
\hline
\end{tabular}

Table 2 shows that among the participants in this study, 53.93 percent has adequate health literacy. Some (36.51\%) of participants had marginal health literacy and only 9.55 percent had inadequate health literacy.

\section{Health literacy level and age}

Age is one of the basic characteristics of the demographic sector, which plays a vital role in determining the health literacy level. In this study, the girl students' health literacy level was same as age increased. The highest health literacy level was appraised in the girls with age 1618 years. The study showed that health literacy level of 16-18 years and 19-21 years was higher than that of girls of aged 22-24 years. Marginal and inadequate health literacy was higher of the girls than girls aged $22-24$ years $(60.71 \%)$ than the girls aged $19-21$ (40\%) and $16-18$ (29.16\%). Similarly, the girls aged 22-24 (10.71\%) years had inadequate health literacy than of $19-21$ and $16-18$ years' age girls. 
Table 3

Health literacy level and age of the respondents

\begin{tabular}{lllllllll}
\hline S.N. & Level & Age & & & & & & Total \\
& & $16-18$ & & $19-21$ & & $22-24$ & & \\
& & No. & $\%$ & No. & $\%$ & No. & $\%$ & \\
\hline I & Inadequate & 7 & 8.54 & 7 & 10 & 3 & 10.71 & 17 \\
2 & Marginal & 24 & 29.16 & 27 & 40 & 17 & 60.71 & 68 \\
3 & Adequate & 51 & 62.50 & 34 & 50 & 8 & 28.57 & 93 \\
Total & & 82 & 46.06 & 68 & 38.20 & 28 & 15.73 & 178 \\
\hline
\end{tabular}

The association between age and health literacy of girl students was not significant. These findings suggest that there is no role of high age to increase health literacy level.

\section{Health Literary Level and Caste}

Caste is a vital character of socio-demographic sector. Caste effects on girls' health literacy. As per caste, the Chhetri (59.25\%) and Janajati $(53.65 \%)$ had more adequate health literary level than the Brahamin (36.46\%) and Dalit (47.05I\%) girls.

Table 4

Health literary according to the caste of the respondents

\begin{tabular}{|c|c|c|c|c|c|c|c|c|c|c|}
\hline \multirow[t]{3}{*}{ S.N. } & \multirow[t]{3}{*}{ Level } & \multicolumn{8}{|c|}{ Caste } & \multirow[t]{3}{*}{ Total } \\
\hline & & \multicolumn{2}{|c|}{ Brahamins } & \multicolumn{2}{|c|}{ Chhetri } & \multicolumn{2}{|c|}{ Janajati } & \multicolumn{2}{|c|}{ Dalit } & \\
\hline & & No. & $\%$ & No. & $\%$ & No. & $\%$ & No. & $\%$ & \\
\hline I & Inadequate & 4 & 10.25 & 7 & 8.64 & 3 & 7.33 & 3 & 17.64 & 17 \\
\hline 2 & Marginal & 20 & 51.28 & 26 & 32.03 & 16 & 41.66 & 6 & 35.29 & 68 \\
\hline \multirow[t]{2}{*}{3} & Adequate & 15 & 36.46 & 48 & 59.25 & 22 & 53.65 & 8 & 47.05 & 93 \\
\hline & Total & 39 & 21.91 & 81 & 49.49 & 41 & 23.03 & 17 & 9.55 & 178 \\
\hline
\end{tabular}

The data presented in table no 4 shows that the association between caste and health literacy of girl students was not significant. The study result shows that there is same health literacy level among so called high caste and lower caste.

\section{Health Literacy Level and Stream}

In this study, girl students of HA/ Staff Nurse were generally associated with adequate health literacy, while the B.Ed. level girls were associated with the marginal and inadequate health literacy (Table5).

Table 5

Health literacy levels of girl students according to streams.

\begin{tabular}{lllllll}
\hline S.N. & Level & \multicolumn{2}{c}{ HA/Staff nurse } & \multicolumn{2}{l}{ B.Ed } & Total \\
& & No. & $\%$ & No. & $\%$ & \\
\hline $\mathrm{I}$ & Inadequate & 3 & 3.33 & 14 & 15.90 & 17 \\
2 & Marginal & 16 & 17.77 & 52 & 59.09 & 68 \\
3 & Adequate & 71 & 78.88 & 22 & 25.00 & 93 \\
& Total & 90 & 50.56 & 88 & 49.43 & 178 \\
\hline
\end{tabular}

According to the table no5, among the total participants of the study, 15.90 percent girls of B.Ed. had inadequate literacy while only 3.33 percent girls of medical science had inadequate health literacy. Likewise, majority (59.09\%) of girls of B.Ed. Level and only 17.77 percent girls 
of health science had marginal health literacy. Similarly, 78.88 percent girls of HA/Staff Nurse had adequate health literacy while only 25 percent girls of B.Ed. had this level of health literacy.

\section{Health Literacy and Years of Level of Education}

The girl students with high education level are more likely to obtain for health-related knowledge. In the presented study, health literacy was increased as the level/year increased.

Table 6

Health literacy and years of education level of girl students

\begin{tabular}{|c|c|c|c|c|c|c|c|c|c|c|c|c|c|c|c|}
\hline \multirow[t]{4}{*}{ S.N. } & \multirow[t]{4}{*}{ Level } & \multicolumn{14}{|c|}{ Level of qualification } \\
\hline & & \multicolumn{6}{|c|}{ H.A/Staff Nurse } & \multirow[t]{3}{*}{ Total } & \multicolumn{6}{|c|}{ B.Ed. } & \multirow[t]{3}{*}{ Total } \\
\hline & & \multicolumn{2}{|c|}{ Ist year } & \multicolumn{2}{|c|}{ 2nd year } & \multicolumn{2}{|c|}{ 3rd year } & & \multicolumn{2}{|c|}{ Ist year } & \multicolumn{2}{|c|}{ 2nd year } & \multicolumn{2}{|c|}{$3 r d$ year } & \\
\hline & & No. & Per. & No. & Per. & No. & Per. & & No. & Per. & No. & Per. & No. & Per. & \\
\hline $\mathrm{T}$ & Inadequate & 3 & 10. & - & - & - & - & 3 & 9 & 30 & 4 & 12.12 & $\mathrm{I}$ & 4 & 14 \\
\hline 2 & Marginal & 9 & 30 & 7 & 21.87 & - & - & 16 & 17 & 56.86 & 23 & $69 . .69$ & 12 & 48 & 52 \\
\hline 3 & Adequate & 18 & 60 & 25 & 78.12 & 28 & 100 & 71 & 4 & 13.33 & 6 & 18.18 & 12 & 48 & 22 \\
\hline & Total & 30 & 33.33 & 32 & 35.55 & 28 & 31.11 & 90 & 30 & 34.04 & 33 & 37.5 & 25 & 28.40 & 88 \\
\hline
\end{tabular}

The study showed that the girls students with first year of HA/Nursing (10.17\%) and B.Ed. (30\%) had inadequate health literacy. Marginal health literary is also more in first year girl students of HA/Nursing $(30.17 \%)$ and B.Ed (56.66\%) than the other levels. The adequate health literacy was higher in girl students of third year of HA/Nursing (100\%) and B.Ed. (48\%). Adequate health literacy in second year of HA/Nursing (78.12\%) and B.Ed. (18.18\%) was more than the girls of HA/Staff Nurse of first year (60\%) and B. Ed (I3.33\%).

\section{Health Literacy and Menstrual Hygiene Management}

Menstrual Hygiene Management (MHM) is the absorption of menstrual blood on clean material which can be changed in privacy. It also incorporates the availability of soap and clean water, to wash re-usable sanitary materials and the body, as well as a suitable place of disposal for used materials (WHO-UNICEF, 20I2). MHM focuses on practical strategies for coping with monthly periods. MHM refers to ways women keep clean and healthy during menstruation and how they acquire, use and dispose of blood absorbing materials (Loughborough University, 2014).

Table 7 shows that, out of total, most (73.59\%) girl students used sanitary pad, 39.95 percent used clean pieces of cloths and 10 percent used both. Out of total 47.05 percent inadequate, 83.82 percent marginal and 70.96 percent adequate literate girl students used sanitary pad. Likewise, most (70.58\%) inadequate, 30.76 percent marginal and 29.03 percent adequate literate girl students used clean pieces of clothes during menstruation.

Table 7

Role of health literacy on menstrual hygiene practice

\begin{tabular}{|c|c|c|c|c|c|c|c|c|c|c|c|}
\hline \multirow[t]{3}{*}{ S.N. } & \multirow[t]{3}{*}{ Level } & \multicolumn{10}{|c|}{ Menstrual hygiene practice } \\
\hline & & \multicolumn{2}{|c|}{ Used pad } & \multicolumn{2}{|c|}{$\begin{array}{l}\text { Use of clean } \\
\text { peace } \\
\text { cloths }\end{array}$} & \multicolumn{2}{|c|}{ Daily sewer } & \multicolumn{2}{|c|}{$\begin{array}{l}\text { Twice } \\
\text { period }\end{array}$} & \multicolumn{2}{|c|}{$\begin{array}{l}\text { One time } \\
\text { during period }\end{array}$} \\
\hline & & No. & Per. & No. & Per. & No. & Per. & No. & Per. & No. & Per. \\
\hline $\mathrm{I}$ & Inadequate & 8 & 47.05 & 12 & 70.58 & 6 & 35.29 & 6 & 35.29 & 5 & 29.41 \\
\hline 2 & Marginal & 57 & 83.82 & 25 & 36.76 & 34 & 50 & 26 & 38.32 & 8 & 11.76 \\
\hline 3 & Adequate & 66 & 70.96 & 27 & 29.03 & 54 & 58.06 & 23 & 24.73 & 18 & 19.35 \\
\hline & Total & $|3|$ & 76.59 & 64 & 39.95 & 94 & 52.80 & 55 & 38.89 & 30 & 16.85 \\
\hline
\end{tabular}


The table 7 also shows the data related to bathing practice of women during menstruation. This table shows that majority $(52.80 \%)$ of girl students took bath once a day, 30.89 percent took bath once in twice a period and 16.85 percent had taken bath one time during period.

Among the girl students, 35.29 percent inadequate literate girl students took bath daily during the period. Likewise, 50 percent of marginal and 58.06 percent of adequate literate girl students took bath in twice a period. Out of total 35.29 percent inadequate, 38.32 percent marginal and 24.73 percent girl took bath in twice a period, out of total inadequate literate (29.41\%), marginal literate (11.76\%) and adequate literate girls (19.35\%) took bath one time during the period.

\section{Discussion}

The findings from situation of health literacy and menstrual hygiene practice of the study participants are discussed here.

\section{Situation of health literacy}

To find out the literacy level of the girl students, S-TOFHLA tool is used. It is functional health literacy assessment tool design to evaluate adult health literacy. Findings of age, streams, cast and years or level of education indicate that health literacy level of the study participants is poor. In this study, the majority of the participants have adequate health literacy category (53.93\%) followed by marginal health literacy $(36.51 \%)$ and inadequate health literacy $(9.55 \%)$ category. Ickes and Cottrell (2010) state that group of university students would seem to have good health literacy levels. Some studies conclude that low health literacy may be associated with poor outcomes in person and high health literacy levels is associated with higher level of health promotion behaviour (as cited in Xu, 20I8). A woman's health literacy is an important element in her ability to engage in health promotion and prevention activities both for herself and her children. (Shieh \& Halstead, 2009, cited as Larson, 20II). Studying more health education-related subjects was associated with a higher health literacy competency, due to these students' higher rates of accessing and understanding health information in the health promotion domain (Vozikis et al., 20l4).

This study displays that the association between age and health literacy of girl students was not significant. These findings suggest that there is no role of high age to increase health literacy level. Some studies suggest that health literacy increases with age. But fewer data is revealed that age is negatively associated with health literacy (as cited in Vozikis, Drivas and Milioris, 2014). Similarly, the data presented in table no 4 shows that the association between caste and health literacy of girl students was not significant. The study result shows that there is same health literacy level among so called high caste and lower caste.

This study showed that health literacy level of girls of $\mathrm{HA} /$ staff nurse was higher than that of girls of B.Ed. The girls of HA/ Nursing are more likely to have health knowledge and health skills. They can obtain theoretical, practical and clinical information and skills. They attend regular in class as well as practical events. It may be stated that health education courses of $B$. Ed level seems not be context relevant and emphases on 'knowledge' and messages, rather than providing practical information and building skills to negotiate health. Inadequate teaching HPE leads girls to have poor health information and skills. So, ineffective teaching trends of health education should be enhanced including critical and interactive teaching opportunities 
(Khanal, 2018). Vozikis, Drivas and Milioris (2014) raise the question of how university health education is related to students' health literacy. We hypothesized that enrolling in health promotion related courses of study would be associated with higher health literacy competency among university students.

Year and level of education is one of the most important positive factors that influence girl student's health literacy level. The adequate health literacy was higher in girl students of third year of HA/Nursing (100\%) and B.Ed. These results suggest that the association between health literacy and level of education of girl students was significant. It seems that health literacy was high as the level increased.

\section{Health Literacy and Menstruation Hygiene Practice}

Out of total, 47.05 percent inadequate, 83.82 percent marginal and 70.96 percent adequate literate girl students used sanitary pad. Majority of adequate literate girl students had taken bath once time during the period. Higher percentage of adequate health literate girl students had used sanitary pad than inadequate health literate and higher proportion of inadequate literate respondents had used peace of clothes as a pad during the period than adequate health literate respondents. This indicates that health literacy level has significant role in using sanitary pad for the period of menstruation period. The data illustration from table no. 7 concludes that bathing practice is affected by respondent's health literacy status.

The findings discussed in this paper provide valuable information that will inform to providers, policy makers and planners to know the situation of health literacy of college girls and will help to approach a strategy of health literacy in the study area. This study has limitations that must be considered. The main delimitation is related to the measurement of health literacy. This study is limited to HPE girl students of Bachelors level and health science of PCL level (HA and Staff Nurse). Therefore, this study does not enable to generalize to all campus going girls in Nepal. So, further study is needed to measure the validity and reliability of the measurement of health literacy.

\section{Conclusion}

In conclusion, the study shows that health literacy level among girl students of campus is unsatisfactory. There is variation in health literacy level on the basis of age, caste, level, stream. The study result shows that there is similar health literacy level between so called high caste and lower cast. The study also concludes that health literacy is high as the level increased. Comparatively, the health literacy of girl students of B. Ed level is not satisfactory than HA and Staff Nurse. It can be concluded that level of health literacy influences the menstruation hygiene practice. This result also specifies that there is a role of health literacy level in menstruation hygiene management of girl students. Therefore, it is recommended that health literacy should be included in educational programme.

\section{References}

Appleton, A. A. (2010). Promoting health literacy through the school nutrition environment. Unpublished Thesis, Masters of Science of, lowa State University. Retrieved fromlib.dr.iastate.edu/cgi/viewcontent.cgi?

Berkman, N. D., Davis, T. C. \& McCormack, L. (2010). Health literacy: What is it? Journal of Health Communication, International Perspectives, 15 (2), Retrieved from https://www.tandfonline.com/doi/full//0.1080/ I08I0730.2010.499985 
Centers for Disease Control and Prevention (2015). Healthy weight-it's not a diet, it's a lifestyle! about BMI for children and teens. Retrieved May 14, 2010, from http://www .cdc.gov/media/subtopic/matte/pdf/03 I 2 laHealthyweightpdf

Hepburn, M. (2016). The relationships between health literacy, self-efficacy and readiness for change to health promotion behaviours in Urban Black Women, Seton Hall University Dissertations and Theses (ETDs). Retrieved from http://scholarship.shu.edu/dissertations/2197

Ickes, M. J. and Cottrell, R. (2010). Health literacy in college students, Retrieved from https://www.ncbi.nlm.nih.gov/pubmed/2030476I

Khanal, S.P. (2018). Role of health literacy in changing health behaviour among the girl student, Unpublished Mini -research Report, Submitted to Research Division, Rectors Office,TU.

Larson, J. L. D. (20II). A descriptive study of rural women 's health literacy about vitamin D.Submitted in partial fulfillment of the requirements for the degree of Masters of Nursing, Montana State University. Retrieved from https://scholarworks.montana.edu/ .../Larson

Liu, Y. B., Liu, L., Li, Y. F. and Chen, Y.L. (20I5). Relationship between health literacy, healthrelated behaviours and health status: a survey of elderly Chinese. International Journal of Environmental Research and Public Health, Retrieved from www.mdpi.com/journal/ijerph.

Loughborough University (20I4). Menstruation hygiene management for school girls. Retrieved from wedcmenstruationhygienemanagement_forschoolgirls.pd.

Mantwill, S. and Schulz, P. J. (20I5). Health literacy in Mainland China: validation of a functional health literacy test in simplified Chinese, Health Promotion International, Volume 3I, Issue 4, Retrieved from https://doi.org// 0.1093/heapro/dav043

Nutbeam, D (2000). Health literacy as a public health goal: a challenge for contemporary health education and communication strategies into the $2 \mathrm{Ist}$ century. Health Promot Int. 2000;15(3):259-268, Retrieved from http://dx.doi.org/ 10.1093/heapro/15.3.259

Speros, C. (2005). Health literacy: concept analysis, Retrieved from https://onlinelibrary.wiley.com/doi/epdf/ I 0.I I I I/j. I 365-2648.2005.03448.x

The Role of Health Literacy (2005). Retrieved from http://www.emhf.org/ resource_images/Navigating Health_FINAL.pdf

Vozikis, A. Drivas, K. and Milioris, K. (20I4). Health literacy among university students in Greece: determinants and association with self-perceived health, health behaviours and health risks, Archives of Public Health, Retrieved fromhttp://www.archpublichealth.com/ content/72/1//5

WHO \& UNICEF (2012). Consultation on draft long list of goal, target, and indicator options for future global monitoring of water, sanitation, and hygiene. WHO/UNICEF joint monitoring programme for water supply and sanitation and hygiene, Retrieved from www.unwater.org

Win, M. Oo, Soe, P. P., Lwin, K. T. (2015). Status and determinants of health literacy: a study among adult population in selected areas of Myanmar, Retrieved from https://www.ijcmph.com/index.php/.../972

Xu, X. Y. (2018). Health literacy, self-efficacy, and associated factors among patients with diabetes. Retrieved from https://www.healio.com/public-health/journals/hlrp/20I8-4-2 